\title{
INVISIBILIZAÇÃO DO ADOECIMENTO PSÍQUICO DO TRABALHADOR: LIMITES DA INTEGRALIDADE NA REDE DE ATENÇÃO À SAÚDE
}

\author{
INVISIBILIZATION OF THE MENTAL ILLNESS OF THE WORKER: THE LIMITS \\ OF COMPREHENSIVENESS IN THE HEALTH CARE NETWORK
}

Cynthia de Freitas Melo (DD (0000-0003-3162-7300)', Ana Karine Sousa Cavalcante (iD) (0000-0002-1063-1688)', Klediane Queiroz Façanha

\author{
${ }^{1}$ Universidade de Fortaleza, Programa de Pós-Graduação em Psicologia, Fortaleza, Ceará, Brasil, \\ $<$ cf.melo@yahoo.com.br> \\ ${ }^{2}$ Universidade de Fortaleza, Departamento de Psicologia, Fortaleza, Ceará, Brasil.
}

Resumo o trabalho tem um papel fundamental para o ser humano se manter socialmente produtivo e reconhecido. Neste contexto, a saúde mental tem recebido uma atenção diferenciada nas últimas décadas. Em meio à precarização, desvalorização do trabalhador, inovações tecnológicas e iminência do desemprego, ocorrem impactos negativos na saúde do trabalhador e, consequentemente, um maior índice de afastamentos por doenças psíquicas. Esta pesquisa objetivou compreender como funciona a assistência à saúde mental do trabalhador no Sistema Único de Saúde em um município do interior do Ceará e se há estabelecimento do nexo causal entre saúde, doença e trabalho. Para tanto, foi realizada uma pesquisa de abordagem qualitativa, que contou com 12 participantes - usuários e profissionais que responderam a um roteiro de entrevista semiestruturado. As informações dos profissionais foram analisadas no software Iramuteq e as dos usuários foram submetidas à análise de conteúdo de Bardin. Os resultados apontam falhas nas ações propostas pelo Centro de Referência em Saúde do Trabalhador, desarticulação dos serviços na rede, dificuldade de investigação do nexo causal e consequente subnotificação dos casos. Conclui-se que é necessário construir articulações entre serviços de saúde para ter uma atenção mais integral em saúde. Palavras-chave saúde do trabalhador; saúde mental; políticas de saúde; Sistema Único de Saúde.
Abstract Work has a fundamental role in keeping the human being socially productive and recognized. In this context, mental health has been gaining distinguishable attention over the past decades. With the precarization, the underestimation of the worker, the technological innovations and the imminence of unemployment, the health of the worker is impacted negatively; consequently, this generates higher rates of absences due to mental illnesses. The present research had the goal of understanding how the care to the mental health of the worker in the Brazilian Unified Health System works in a municipality of the state of Ceará (Brazil), and if there is the establishment of a causal nexus among health, illness and work. In order to do so, we developed a qualitative research comprised of 12 participants - users and professionals who answered a semistructured interview form. The information provided by the professionals was analyzed using the Iramuteq software, and that of the users was submitted to Bardin's content analysis. The results indicate faults in the actions proposed by the Worker Health Reference Center, a lack of connection with the services in the network, difficulty in investigating the causal nexus, and a consequent underreporting of the cases. We concluded that it is necessary to develop connections among the health services in order to get a health care that is more comprehensive.

Keywords occupational health; mental health; health policies; Unified Health System. 


\section{Introdução}

Em 1946, a saúde foi conceituada pela Organização Mundial da Saúde (OMS) como um estado de completo bem-estar físico, mental e social. Esse conceito posiciona, de forma diferenciada, o contexto social e mental que, até então, não era percebido como determinante ao se falar em saúde. A saúde era entendida apenas como ausência de doença, em uma visão puramente física (Pinto et al., 2011).

Fundamentada na compreensão da existência de múltiplos determinantes sobre a saúde, da integralidade do sujeito e da importância do trabalho na sua constituição, a saúde mental no trabalho tem recebido uma atenção diferenciada nas últimas décadas (Seligmann-Silva et al., 2010). Essa preocupação é reforçada pelo contexto de precarização, desvalorização do sujeito, inovações tecnológicas e iminência do desemprego, que acarretam impactos negativos na saúde do trabalhador e, consequentemente, em um maior índice de afastamentos por doenças psíquicas. Além disso, os riscos à integridade física e, principalmente, à forma de gestão imposta por meio de metas de produtividade e organização do tempo, desconsideram os limites físicos e psicológicos dos trabalhadores. Como consequência, a literatura destaca que os transtornos mentais atingem 30\% dos trabalhadores ocupados e podem estar associados a quadros de afastamentos prolongados, consumo de drogas, acidentes de trabalho e até mesmo de exclusão do mercado de trabalho (Duarte e Almeida, 2015; Paparelli, Sato e Oliveira, 2011; Silva e Merlo, 2007; Silvestre e Sabino, 2011).

Nesse cenário de valorização da saúde no contexto do trabalho, foi instaurado o conceito de Saúde do Trabalhador (ST), que é definido como um conjunto de ações que se destinam à promoção, proteção, recuperação e reabilitação da saúde dos trabalhadores. Essa proposta consiste também em avaliar, por meio de vigilância epidemiológica e sanitária, os riscos e agravos advindos das condições de trabalho, regulados pela lei n. 8.080, de 1990 (Brasil, 1990). Por meio de uma prática interdisciplinar, com gestão participativa, pressupõe-se tanto um caráter intrassetorial quanto intersetorial. O primeiro abrange todos os níveis de atenção e esferas de governo do Sistema Único de Saúde (SUS) enquanto o segundo envolve a Previdência Social, do Trabalho e do Meio Ambiente, além da Justiça, da Educação e dos demais setores relacionados às políticas de desenvolvimento (Brasil, 2010; Melo et al., 2013; 2014; Melo et al., 2017).

Para a operacionalização da informação, vigilância, capacitação, pesquisa e educação em ST, o Ministério da Saúde criou, em 2002, uma portaria que dispõe sobre a estruturação da Rede Nacional de Atenção Integral à Saúde do Trabalhador (Renast). Tal legislação tem o propósito de articular ações de promoção, prevenção e recuperação da saúde dos trabalhadores, independente do 
vínculo empregatício. Em sua organização, a atenção à saúde do trabalhador, prioritariamente a saúde mental, segue a lógica de hierarquização do SUS, feita nos três níveis de atenção. Na atenção primária, na Estratégia de Saúde da Família (ESF) e no Núcleo de Apoio à Saúde da Família (Nasf); na atenção secundária, nos Centros de Referência em Saúde do Trabalhador (Cerest), por meio de acesso direto ou por encaminhamento das ESFs, após estabelecimento de nexo causal entre saúde e trabalho; e na atenção terciária, nos serviços de média e alta complexidades. Desse modo, quando um trabalhador possui uma queixa de saúde, seja ela física ou mental, deve ir para a ESF, que é a porta de entrada do serviço do SUS, e, de lá, ser encaminhado ao Cerest. Também poderá procurá-lo diretamente (Brasil, 2010; Campos e Domitti, 2007; Leão e Vasconcelos, 2011; Santos e Lacaz, 2012; Silva, 2013; Soares e Linhares, 2008).

Para melhor registro e controle do nexo causal entre saúde e doença psíquica e trabalho, em 2004, o transtorno mental relacionado ao trabalho foi definido como um dos agravos de notificação compulsória por meio da Portaria GM/MS n. 777 (revogada pela Portaria GM/ MS n. 104, de 2011) (Brasil, 2004; 2011). Portanto, todos os profissionais da rede de saúde devem realizar a notificação junto ao Sistema de Informação de Agravos de Notificação (Sinan) diante da suspeita ou confirmação de doença ou agravo. Neste caso, também cabe ao Cerest manter os profissionais capacitados para a realização da notificação e utilização do Sinan (Machado, 2005; Medina e Maia, 2016).

Apesar de toda a rede de assistência à saúde do trabalhador existente no SUS, ainda se nota que há um despreparo entre os profissionais em lidar com questões de sofrimento mental no trabalho e realizar a relação de nexo causal (Bernardo e Garbin, 2011; Silva et al., 2012). Observa-se, pois, que esses trabalhadores-usuários, muitas vezes, ficam sem assistência, sem relação de nexo causal. São atendidos na ESF sem encaminhamento ao Cerest ou encaminhados aos Centros de Atenção Psicossocial (Caps), com verificação de doença mental, sem associação com o trabalho (Cardoso e Araújo, 2016; Machado et al., 2013; Poço e Poço, 2015). Diante do exposto, o objetivo da presente pesquisa é compreender como funciona a assistência à saúde mental do trabalhador no SUS em um município do interior do Ceará (Brasil) e se há estabelecimento do nexo causal entre saúde, doença e trabalho.

\section{Métodos}

Pesquisa de abordagem qualitativa que visa aprofundar o estudo acerca do percurso do trabalhador em sofrimento psíquico nos serviços públicos de saúde. Por critério de saturação, contou-se com 12 participantes: três trabalhadores usuários do Cerest e que já tiveram algum transtorno mental relacionado ao trabalho, dois profissionais da ESF - 1 (um) médico e 1 (um) enfermeiro -, 
dois profissionais do Nasf - 1 (um) assistente social e 1 (um) psicólogo -, dois profissionais do CAPS - 1 (um) psiquiatra e l (um) psicólogo - e três profissionais do Cerest - l (um) médico, l (um) enfermeiro e l (um) psicólogo.

Foram utilizados três roteiros de entrevista semiestruturada, adaptados a cada grupo. Para os profissionais do Cerest, o roteiro continha as seguintes categorias: Responsabilidades do Cerest e Encaminhamento do usuário. Para os profissionais da ESF e Caps, o roteiro continha as seguintes categorias: Encaminhamento do usuário, Relação com o trabalho e Orientação Política Saúde do Trabalhador. Para os trabalhadores usuários do Cerest, as seguintes categorias: Atenção à Saúde; e Relação com o trabalho.

Para análise de dados das entrevistas com os profissionais, foi utilizado o software Interface de R pour les Analyses Multimensionnelles de Textes et de Questionnaires (Iramuteq). Foram realizadas análises lexicográficas clássicas para verificação de estatística de quantidade de evocações e formas e obtevese a Classificação Hierárquica Descendente (CHD) para o reconhecimento do dendograma com as classes que surgiram, desconsiderando as palavras com $\mathrm{x}^{2}>3,80(\mathrm{p}<0,05)$ (Camargo e Justo, 2013).

Para a análise de dados das entrevistas com os usuários, foi utilizada a Análise de Conteúdo de Bardin, que se ocupa, basicamente, da análise das mensagens e possui como característica a orientação empírica, exploratória, vinculada a fenômenos reais e de finalidade preditiva (Fonseca, 2005). Para o desenvolvimento da técnica, foi utilizada a estrutura de etapas recomendadas: 1) organização da análise; 2) codificação da mensagem; 3) categorização (ver na análise das entrevistas) e 4) inferência. Após todo esse processo, têm-se as conclusões como respostas de um trabalho de pesquisa orientado sempre por seus objetivos (Bardin, 1997).

O projeto foi aprovado por comitê de ética em pesquisa, por meio do parecer n. 2.366.341. Foram seguidas todas as normas para pesquisa com seres humanos, de acordo com as Resoluções n. 466/12 e 510/16 e as entrevistas foram realizadas de forma individual, com auxílio de gravador, em sala reservada.

\section{Análise dos resultados das entrevistas dos profissionais}

O corpus geral de discursos dos profissionais foi constituído por nove textos (entrevistas), separados em 387 segmentos de texto (ST), com aproveitamento de 303 ST (78,3\%). Emergiram 13.996 ocorrências (palavras, formas ou vocábulos), sendo 2.035 palavras distintas e 1.031 com uma única ocorrência. O conteúdo analisado foi categorizado em cinco classes: Classe 1 - Ações do Cerest, com 65 ST (21,45\%); Classe 2 - Acolhimento na Renast e investigação do nexo causal, com 56 ST (18,48\%); Classe 3 - Estabelecimento do nexo causal e trabalho em rede, com 56 ST (18,48\%); Classe 4 - Falhas na Renast, 
com 60 ST $(19,80 \%)$ e Classe 5 - Subnotificação, com 66 ST $(21,78 \%)$. A seguir serão descritas, operacionalizadas e exemplificadas cada uma dessas classes.

\section{Classe 1 - Ações do Cerest}

Estão elencadas nesta classe as ações realizadas pelos profissionais do Cerest, em sua rotina de trabalho. É dada ênfase para a forma de acesso do usuário ao serviço e o foco dos profissionais nessa abordagem inicial. Falam das ações de notificação no Sinan e ambiguidade da legislação sobre a atribuição dessa responsabilidade. Abordam as ações de capacitação que oferecem aos profissionais dos diferentes serviços de saúde sobre o nexo causal saúde e trabalho. Contemplam as ações realizadas de vigilância em saúde, abrangendo a parceria das vigilâncias epidemiológica, ambiental e sanitária.

Os profissionais relatam que a entrada do usuário no serviço pode acontecer por meio de notificação, demanda espontânea, denúncia ou sistema de informação. Nesse primeiro contato com o usuário, o foco dos profissionais está na coleta de informações sobre a causa das doenças e agravos dos usuários, conforme pode ser observado no exemplo:

Vem de demanda espontânea do próprio trabalhador, fazendo a denúncia, ou ela vem a partir das notificações, quando se notifica um caso de acidente de trabalho em qualquer ponto da rede ou de adoecimento, [...] ela vem pelo Ministério Público ou por algum órgão intersetorial (Participante 3, profissional do Cerest).

Corroborando este relato, Machado et al. (2013) revelam em seu estudo que a origem da demanda dos Cerests vem por meio do Ministério Público, sindicatos, denúncia, demanda espontânea ou encaminhamentos de outros serviços. Sobre esse aspecto, Silva (2012) ressalta que, apesar das várias possibilidades de entrada do usuário na Renast, na maioria dos casos, o Cerest funciona como porta de entrada da rede, ou seja, mediante a demanda espontânea do próprio trabalhador. Como consequência, as ações de assistência ainda são priorizadas em detrimento das ações de vigilância e controle epidemiológico.

Em complementação, Poço e Poço (2015) relatam que as informações iniciais coletadas durante o acolhimento no Cerest visam à avaliação da suspeita de doença ocupacional ou acidente do trabalho. Quando estes são indicados, os encaminhamentos internos (consulta com médico, psicólogo, fonoaudiólogo) ou externos (outros serviços de saúde, Instituto Nacional do Seguro Social, sindicatos, Ministério do Trabalho, Promotoria Pública etc.) são realizados, bem como são fornecidas orientações legais (trabalhistas e previdenciárias). 
Sendo assim, os atendimentos realizados por profissionais deste serviço objetivam o estabelecimento do nexo causal e não a assistência ao trabalhador.

Os discursos dos participantes evidenciaram uma contradição na legislação em vigor no município quando se trata da obrigatoriedade da notificação de transtornos mentais relacionados ao trabalho (TMRT). Afirmam que não há clareza sobre a quem cabe a responsabilidade de notificar: unidade de referência, unidade-sentinela ou qualquer serviço.

A gente tem batido na tecla de que a notificação compulsória, dentro do desenho da epidemiologia... inclusive a lei que fala da questão da vigilância sanitária epidemiológica da década de 1970 já traz isso: a responsabilidade do profissional de saúde dentro da saúde pública de não se omitir, podendo responder por essa omissão (Participante 3, profissional do Cerest).

Hoje, a portaria diz que só a unidade-sentinela tem a obrigação de notificar; no entanto, quando se volta na lei de vigilância epidemiológica, ela diz que todo profissional de saúde, capaz de reconhecer um adoecimento, não pode se omitir perante ele (Participante 3, profissional do Cerest).

Ressalta-se que essa duplicidade de informações trazidas pela portaria n. 777, de 28 de abril de 2004, que dispõe sobre os procedimentos técnicos para a notificação compulsória de agravos à Saúde do Trabalhador em rede de serviços-sentinela no SUS, pode acarretar uma omissão dos profissionais da Renast. Estes podem concluir que apenas os profissionais da rede-sentinela são capacitados para realizar o nexo causal e a notificação no Sinan (Brasil, 2004). Destaca-se, ainda, que, no município pesquisado, o Caps é indicado como uma unidade-sentinela juntamente com o Cerest e o Centro de Especialidades Médicas (CEM), responsáveis pela notificação de TMRT (Torres et al., 2016). Outras unidades de saúde, como a ESF, permanecem, todavia, formalmente excluídas da rede-sentinela, reforçando a não notificação de casos e falha em toda a rede.

Este fato reforça a necessidade de maior oferta de capacitações constantes para os profissionais de saúde de todos os serviços de saúde do SUS. Dessa forma, é possível melhorar a compreensão sobre o nexo causal entre saúde e trabalho, estreitar o vínculo entre os serviços e fortalecer o Cerest como referência técnica na rede. A literatura destaca a capacitação em saúde do trabalhador como uma ação estruturante do Cerest e o posiciona como referência técnica na Renast (Leão; Vasconcelos, 2011; Machado, 2005). No entanto, esta ação torna-se um limitante quando a equipe delimitada não consegue atender à demanda territorial. 
Os profissionais também salientam a participação do Cerest no contexto de Vigilância em Saúde, abrangendo Vigilância Epidemiológica, Vigilância Ambiental e Vigilância Sanitária. No exemplo a seguir, o profissional destaca a necessidade da proximidade de atuação com a Vigilância Ambiental e Sanitária, facilitando, inclusive, a atuação na Vigilância em Saúde do Trabalhador (VST), visto que a Vigilância Sanitária tem poder de polícia, enquanto o Cerest, não.

A vigilância de ambiente e processo de trabalho, na saúde do trabalhador, tem uma ligação muito forte com a vigilância sanitária e com a vigilância ambiental. Muitos estabelecimentos que eles inspecionam enquanto saúde do trabalhador, eles também levam a vigilância sanitária juntos, pois como eles não têm o poder de polícia dentro da constituição, dentro do que se constitui o Sistema Único de Saúde (...) A única vigilância que tem esse poder de polícia, do estado de fiscalização, é a vigilância sanitária. Então é uma parceria que tende a se fortalecer na inspeção de estabelecimentos porque assim se consegue entrar em qualquer estabelecimento que seja passível de vigilância e ver também as questões de saúde do trabalhador (Participante 1, profissional do Cerest).

Sobre esse aspecto, Machado (2005) ressalta que as experiências de implantação de ações de VST, em vários pontos do Brasil, resultaram em uma gama de experiências distintas. Essas várias formas de intervenção configuram o campo de VST como um processo social em que vários atores executam seu protagonismo em vários níveis de ação (executivo e legislativo) organizados visando à promoção da saúde do trabalhador. Percebe-se que, no município estudado, a estrutura, inclusive física, foi organizada para que o contexto de VST pudesse ser implementado em parceria com as três vigilâncias. Coerente com a diretriz de descentralização do SUS, o município assumiu as atribuições e responsabilidades da Vigilância em Saúde, de forma a realizar a integração das informações, dados e ações dos serviços (epidemiológico, sanitário, ambiental). Nesse contexto, foi criada, em 1997, a Coordenação de Vigilância à Saúde (Soares e Linhares, 2008).

\section{Classe 2 - Acolhimento na Renast e investigação do nexo causal}

Nesta classe, são relatados o processo de entrada e acolhimento dos usuários na Renast e o papel do Cerest de investigação do nexo causal (e não de assistência). Também será mencionada a dificuldade em se manter um Projeto Terapêutico Singular (PTS), mediante a não continuidade dos usuários nos serviços, causando o não estabelecimento do nexo causal e consequente subnotificação. 
Relata-se que, assim como no Cerest (apresentado na Classe 1), o processo de acolhimento de entrada do usuário na Renast pode acontecer por demanda espontânea ou por referenciamento (encaminhamento) realizado por quaisquer níveis de atenção à saúde. Quando a entrada ocorre por meio de serviços de outras redes, como a ESF e o Caps, o acolhimento acontece por qualquer profissional da equipe multiprofissional que estiver demandado para tal função, sendo, em seguida, referenciado para o Cerest. Quando a entrada ocorre diretamente pelo Cerest, este acolhimento é feito por meio do enfermeiro ou, quando se trata de transtornos mentais, ressalta-se a relevância da avaliação do psicólogo em parceria, para, somente assim, se iniciar o processo de investigação do nexo causal.

Ressalta-se, entretanto, que a portaria n. 1679, de 19 de setembro de 2002, orienta que a porta de entrada da Renast seja a Atenção Primária e os serviços de urgência e emergência (Brasil, 2002). Neste contexto, cabe ao Cerest posicionar-se como suporte técnico e científico, orientando os demais serviços para que possam atender os agravos à saúde relacionados ao trabalho.

Os participantes ressaltam que os profissionais do Cerest não são responsáveis pela assistência à saúde do trabalhador. Este encargo está delimitado a outros serviços, como a ESF e o Caps. Cabe ao Cerest a responsabilidade de investigação do nexo causal. Esse processo de investigação poderá ocorrer em vários encontros, porém eles não têm caráter terapêutico e sim de investigação, conforme relato:

A nossa grande frente de trabalho é fazer o apoio matricial. Assim como está especificado na política, a gente não faz assistência, o que a gente faz é acolhimento. Se precisar também mais vezes pra fechar nexo causal, a gente vai marcar outros atendimentos (Participante 2, profissional do Cerest).

Esse dado corrobora com a pesquisa de Cardoso e Araújo (2016), que evidenciaram que os casos atendidos pelos Cerests pesquisados eram, frequentemente, encaminhados para a assistência na Rede de Atenção Psicossocial, principalmente para os Capss e ambulatórios em saúde mental e para a Atenção Primária.

Ressalta-se também a dificuldade em se manter um Projeto Terapêutico Singular (PTS), tendo em vista a ocorrência de situações nas quais o paciente se 'perde' na rede e desiste dos atendimentos antes de ser realizado o nexo causal. Esta desistência dos atendimentos torna-se um fato preocupante, porque ocorre antes de ser efetuada a notificação no Sinan, reforçando a subnotificação.

A gente perde muito esses usuários (...) Eles passam pelo primeiro atendimento, mas eles se perdem; a gente não consegue seguir o projeto terapêutico singular seja porque ele retornou ao trabalho ou talvez seja por desconhecimento (...) talvez 
essa queixa não chegue ao Cerest porque o trabalhador não tem a compreensão que o Caps faz parte da rede de apoio que vai prestar assistência nessa situação do sofrimento psíquico (Participante 4, Psicólogo, Caps).

Sobre esse aspecto, Pinto et al. (2011) revelam, em sua pesquisa, os desafios da construção do PTS dos usuários do Caps Geral de Sobral, Ceará. Os autores ressaltam a importância de o projeto ser elaborado com base nas necessidades de saúde de cada usuário, levando em consideração seu modo de compreender a vida, suas subjetividades e singularidades, configurando-se numa interação democrática e horizontal entre os atores envolvidos no processo de cuidar (trabalhadores, usuário, família). Sendo assim, quando ocorre esta desistência, é um indicativo de falha no processo de construção, não somente do PTS, como também falha na vinculação do usuário com a Renast. De forma complementar, Medina e Maia (2016) relacionam a desistência do PTS à subnotificação dos agravos no Sinan. Os autores concluem que essa falha também está ligada ao desconhecimento do papel de cada profissional na identificação e notificação do agravo, à insuficiência do trabalho em equipe e à desvalorização da notificação por parte de alguns profissionais.

\section{Classe 3 - Estabelecimento do nexo causal e trabalho em rede}

Estão elencados nesta classe aspectos relacionados ao trabalho integrado em rede intra e intersetorial. Os participantes relataram a forma de realização do estabelecimento do nexo causal e a necessidade de trabalho em parceria entre os profissionais do Cerest e destes com outros serviços. Relataram, ainda, a importância da comunicação entre profissionais e serviço, bem como monitoramento dos atendimentos do usuário, por meio da referência e contrarreferência. Por fim, contemplam a importância e a dificuldade em realizar o matriciamento.

O estabelecimento do nexo causal ocorre, sobretudo, em parceria. Esta pode ocorrer intrasserviço, entre os profissionais do Cerest ou interserviços, dos profissionais do Cerest com profissionais da ESF e Caps. Para tanto, é reforçada a importância de envolver outros profissionais e outros serviços de atenção à saúde para o estabelecimento do nexo causal.

Sempre passavam por mim esses casos suspeitos de doenças relacionadas ao trabalho. Eu fazia a anamnese, o exame físico e avaliava exames complementares. Quando eu tinha dúvida, solicitava à equipe de vigilância para fazer a vigilância do ambiente de trabalho e quando eu coletava todas essas informações eu estabelecia a relação de nexo causal (Participante 1, profissional do Cerest). 
Eu sempre tento incentivar que a nossa rede-sentinela faça essa notificação ou, que pelo menos, a atenção primária faça a notificação. Por exemplo, quando eu recebo algum caso, eu sempre tento contatar a equipe de atenção primária, que é do território do paciente, pra gente fazer a discussão de caso pra ver se consegue fechar o nexo causal (Participante 2, profissional do Cerest).

Segundo a Política Nacional de Saúde do Trabalhador (PNST), a rede ambulatorial especializada - no caso da saúde mental - deve estabelecer a suspeita ou identificação da relação com o trabalho, de forma articulada com a equipe técnica do Cerest sempre que necessário. Além disso, essa rede deve ser responsável pelo diagnóstico, tratamento e reabilitação, que já fazem parte de suas funções (Brasil, 2012). A pesquisa de Cardoso e Araújo (2016) evidenciou, entretanto, que as ações de inspeção para investigação de riscos psicossociais ainda são tímidas entre os Cerests pesquisados.

Também foi ressaltada a importância do trabalho em rede sempre seguido de uma comunicação dos casos e acompanhamento do atendimento dos usuários nos serviços. Comunicação que deve ser estabelecida por meio da referência e contrarreferência:

A orientação é que, após o atendimento, seja feita a contrarreferência para quem solicitou o atendimento. Então, é repassado para o profissional que solicitou através da ficha de referência própria do SUS com observações e orientações do que pode ser feito em relação àquele trabalhador a terapia individual ou em grupo para que ajude esse trabalhador a se fortalecer e enfrentar o processo (Participante 1, profissional do Cerest).

A referência e contrarreferência constituem-se em um problema generalizado no SUS, pois o que se vê na prática são falhas de contrarreferenciamento à atenção primária, ocasionando problemas de comunicação sobre o atendimento aos usuários (Melo et al., 2013; 2014; 2017). Por tudo isso, cabe ao Cerest o monitoramento dos casos articulados por uma comunicação eficaz por meio da referência e da contrarreferência, para se garantir uma atenção integral aos trabalhadores (Cardoso e Araújo, 2016).

Além disso, ressalta-se a importância do matriciamento e a dificuldade de realizá-lo. Percebe-se que ainda há falhas nesta articulação intersetorial e as redes - Renast e Rede de Atenção Psicossocial (Raps) - ainda não conversam entre si nem se complementam.

A nossa grande frente de trabalho é fazer o apoio matricial assim como está especificado na política. A gente não faz assistência, o que a gente faz é acolhimento. A gente acolhe a demanda do usuário que chega, seja por demanda espontânea, ou por demanda referenciada (Participante 2, profissional do Cerest). 
A orientação é essa: o Cerest não é pra fazer o atendimento em si... é pra fazer esse apoio matricial, esse suporte técnico e fazer as redes conversarem (Participante 3, profissional do Cerest).

Segundo Campos e Domitti (2007), o apoio matricial e a equipe de referência são metodologias de trabalho para se realizar a gestão da atenção em saúde que busca diminuir a fragmentação imposta ao processo de trabalho decorrente da especialização. Assim, pode-se compartilhar a responsabilidade pelos casos, delimitando o papel de cada profissional e serviço. Cabe à equipe de referência a responsabilidade pelo seguimento longitudinal e pela construção de uma lógica que procure integrar a contribuição dos vários serviços, departamentos e profissionais. No que tange ao campo Saúde do Trabalhador, Santos e Lacaz (2012) relatam que, após a estruturação do apoio matricial e adesão da rede básica aos conceitos e práticas do campo ST, o Cerest se torna, de fato, referência especializada para ações em ST, conforme preconizado na Renast.

\section{Classe 4 - Falhas na Renast}

A constatação de um distanciamento do Cerest em relação aos demais serviços de saúde propiciou o desconhecimento de outros profissionais sobre as ações do referido Centro. Foi reforçada a insuficiência de capacitações oferecidas pelo Cerest aos profissionais de outros serviços. Estes relataram o desconhecimento do Sinan. Foram apresentados problemas na articulação dos serviços de saúde na cidade. Por fim, foram relatadas dificuldades em estabelecer o nexo causal.

Constatou-se que um dos problemas operacionais da Renast está no distanciamento das ações do Cerest em relação aos demais serviços. Como consequência, os profissionais dos outros serviços (ESF, Nasf e Caps) afirmaram o desconhecimento sobre as atribuições do Cerest, conforme exemplos:

Eu não tenho contato nenhum com o Cerest. Não sei se é desinformação minha, mas eu como médica, não tenho nenhuma relação com o Cerest. Para falar a verdade, eu não sei quais são as funções do Cerest. Eu acho que é uma falha da nossa formação, a gente não tem contato com a função desses órgãos (Participante 5, Médico, Caps).

Sobre este tema, Leão e Vasconcellos (2011) relatam que parece não haver clareza da missão institucional da Renast. Ao contrário de outras redes que concentram sua atuação no desenvolvimento de políticas de saúde, a Renast parece não concentrar esforços para se fortalecer como Política de Saúde do Trabalhador. Diante disso, há uma falta de esclarecimento sobre as atribuições 
e, acima de tudo, sobre a razão de existir, colocando em risco as conquistas dos trabalhadores.

Ficou evidente que, apesar dos profissionais do Cerest oferecerem capacitações para profissionais de outros serviços, alguns participantes (da ESF) afirmaram nunca ter assistido ou tomado conhecimento dessas ações, confirmando que elas não possuem abrangência e são insuficientes (Cardoso e Araújo 2016):

Não, nunca participei de alguma ação de orientação do Cerest, nunca presenciei alguma ação de promoção, proteção ou reabilitação à saúde mental do serviço (Médico, ESF).

Nunca presenciei nenhuma ação do Cerest em meu local de trabalho. Uma das dificuldades que encontro é de não conseguir conhecer os serviços porque aqui é sempre lotado (Participante 8, Psicólogo, ESF).

Os profissionais do Caps e ESF também relataram um desconhecimento e distanciamento com relação ao Sinan, corroborando Santos e Lacaz (2012):

Eu, particularmente, nunca notifiquei. Não conheço o Sinan, também nunca tive interesse em conhecer. Acho que se tivesse esse momento facilitariam as coisas (Participante 5, Médico, CAPS).

Conheço o Sinan, mas nunca realizei nenhuma notificação (Participante 9, Assistente Social, ESF).

Analisando o relato dos profissionais, pode-se perceber uma desarticulação dos serviços na rede. Corroborando com este relato, Campos e Domitti (2007) sinalizam que a divisão tradicional do trabalho em saúde dificulta a integração da atenção e do cuidado das pessoas, estabelecendo um alto grau de departamentalização e divisão entre os profissionais. Desta forma, os autores sugerem facilitar a comunicação entre distintos especialistas e profissionais e montar um sistema que produza um compartilhamento de responsabilidades pelos casos, esclarecendo o papel de cada serviço e de cada profissional.

Outro problema que a gente tem aqui é a dificuldade em articular o serviço. A gente tem, infelizmente, uma rede muito falha em alguns pontos. A gente, muitas vezes, não consegue um retorno e acaba dificultando esse encaminhamento (Participante 9, Assistente social, ESF). 
Também foi sinalizada dificuldade em estabelecer nexo causal, corroborando a literatura (Paparelli, Sato e Oliveira, 2011; Cardoso e Araújo, 2016). Esse fato agrava-se ainda mais, por haver duas áreas, saúde mental e saúde do trabalhador, que, ao longo de décadas, vêm realizando suas ações de forma isolada entre si (Bernardo e Garbin, 2011):

A gente tenta fazer essa investigação de uma forma bem superficial, mas, muitas vezes, a gente não tem como provar que está realmente vinculada ao trabalho. A gente suspeita que esteja, até pelo próprio relato do paciente, mas não consegue provar, de fato, que foi por conta do trabalho... principalmente os adoecimentos de saúde mental, porque os outros adoecimentos são bem mais fáceis, quando são físicos, do que o de cunho de saúde mental (Participante 9, Assistente social, ESF).

\section{Classe 5 - Subnotificação}

São elencadas as dificuldades práticas de se realizar a notificação de nexo causal entre saúde e trabalho, fato que vai culminar em uma subnotificação dos casos de TMRT. Um dos problemas para a realização do nexo causal elencado pelos participantes refere-se à necessidade da participação do médico nesse processo, devido à obrigatoriedade de classificação no CID-10. Ele não é o único profissional que pode estabelecer, mas, necessariamente, precisa estar envolvido, conforme indicado nos exemplos:

Sempre vai precisar de um médico para estabelecer o diagnóstico da doença porque, muitas vezes, o profissional tem várias evidências de que aquele adoecimento veio por conta das situações relativas ao trabalho, mas é necessário um médico para poder fechar o nexo causal (Participante 1, profissional do Cerest).

Todas as fichas de notificação de todos os agravos têm um campo que você precisa colocar o diagnóstico. Nenhum outro profissional pode porque o diagnóstico cabe ao médico... pode ser o médico do Caps (Participante 1, profissional do Cerest).

Essa obrigatoriedade da participação do médico torna-se um problema na rede de atenção à saúde do trabalhador no município estudado, visto que o Cerest não possui este profissional em sua equipe. Assim, diante da ausência de médico no referido centro, o psicólogo do Centro tem que encaminhar o trabalhador ao Caps (que possui médico) para fechamento do nexo causal. Por outro lado, os profissionais do Caps alegam que não possuem conhecimento técnico que assegure a realização do nexo. O depoimento a seguir reflete essa afirmativa. 
A gente não notifica. Não é uma orientação da rede. Eu acho que nós, enquanto profissionais, não conseguimos. A relação Cerest e Caps ainda está sendo construída. A gente já identifica a relação desse adoecimento com o trabalho e a gente dá os encaminhamentos, por exemplo, para uma intervenção grupal mais relacionada ao trabalho (Participante 4, Psicólogo, CAPS).

Eu também não faço essa notificação. Eu sempre converso com a assistente social, mas eu não notifico... pode ser até uma falha nossa (Participante 5, Médico, CAPS).

Tais dificuldades corroboram a literatura, que relata ausência de profissionais em serviços de saúde, especialmente o médico (Melo et al., 2013; 2014; 2017) e insegurança técnica dos profissionais para o estabelecimento do nexo causal (Santos e Lacaz, 2012).

\section{Análise dos resultados dos discursos dos usuários}

O corpus dos discursos dos usuários é constituído pelo conteúdo das três entrevistas - Unidades de Contexto Inicial (UCI), distribuídas em 585 Unidades de Contexto Elementar (UCE), com aproveitamento de 95,5\%. As UCEs foram distribuídas em quatro classes temáticas distintas, nomeadas com títulos que remetem aos seus conteúdos: 1) O processo de adoecimento e a relação com o trabalho; 2) Percurso do trabalhador na Renast; 3) Ausência de ações do Cerest; e 4) Investigação do nexo causal.

\section{Classe temática 1 - 0 processo de adoecimento e a relação com o trabalho}

A classe temática 1 (425 UCEs; 76,4\% do corpus total) remete ao processo de adoecimento dos usuários do Cerest e a relação que eles estabelecem entre a doença e o seu contexto do trabalho. São contempladas as principais causas do adoecimento dos participantes, como a pressão sofrida no trabalho por cumprir metas, o assédio moral, a falta de identificação com a atividade laboral e a incapacidade física proveniente de Lesões por Esforços Repetitivos (LER) e Distúrbios Osteomusculares Relacionados ao Trabalho (Dort).

Tinha muitas pressões por metas. Pra você ter uma ideia, no ano passado eu fui quem cumpriu mais metas da equipe toda. Fui eu que recebi mais remuneração variável. Só que, além dessa questão da pressão por cumprir metas e entregar os trabalhos no prazo, começou a ter uma série de outras coisas, como assédio moral (Participante 1). 
A pressão sofrida no trabalho para o cumprimento de metas, segundo Seligmann-Silva et al. (2010), é uma forma de organização ou política de gerenciamento que desconsidera os limites físicos e psíquicos do trabalhador. Nesse sentido, impõe-lhe, frequentemente, a anulação de sua subjetividade para que a produção não seja prejudicada e as metas estabelecidas sejam cumpridas. O assédio moral praticado no contexto laboral é apontado, na literatura, como um fator que pode levar o trabalhador a desenvolver diversas enfermidades, incluindo transtornos mentais (Duarte e Almeida, 2015). A falta de identificação com a atividade laboral está ligada a uma atividade que não gera prazer, não gera reconhecimento (Silva e Merlo, 2007). A incapacidade física proveniente das lesões (LER) e dos distúrbios (Dort) é apontada na literatura como um círculo vicioso de dor e sofrimento mental que interfere negativamente na vida familiar, profissional e social do trabalhador (Silvestre e Sabino, 2011).

\section{Classe temática 2 - Percurso do trabalhador na Renast}

A classe temática 2 (50 UCEs; 9,0\% do corpus total) remete aos encaminhamentos realizados, inicialmente, na rede, a partir da porta de entrada no serviço, até o usuário ser atendido no Cerest. Verificou-se que, do total de três usuários entrevistados, dois buscaram diretamente o Cerest por demanda espontânea. O participante 1 já estava em acompanhamento psicoterápico e psiquiátrico em consultório privado e procurou o Cerest por indicação do psicólogo particular, para obter seu benefício previdenciário. A participante 2 buscou o referido Centro por indicação de uma vizinha, uma vez que na ESF foi informada que deveria solicitar tratamento na empresa em que trabalhava, conforme relato:

Procurei o posto de saúde, mas foi o mesmo que nada. Quando eu estava trabalhando, eles diziam que eu tinha que procurar era lá na empresa. Eles ficavam com raiva, diziam: lá no seu trabalho tem atendimento, por que você não busca atendimento lá? Lá tem médico! Então eu procurava muito pouco o posto, só se fosse muita necessidade. A maioria das vezes eu procurava o ortopedista particular que eu já fazia acompanhamento com ele (Participante 2).

Já a Participante 3 procurou, inicialmente, a ESF (Atenção Primária). Em seguida, por se tratar de sofrimento psíquico, foi encaminhada ao Caps e medicada. Apenas após alguns meses, quando resistiu ao tratamento e relatou a relação do seu sofrimento com o seu trabalho, foi direcionada ao Cerest. 
Onde eu chegava, eu chorava [...] Foi aí que procurei o posto de saúde. Então o enfermeiro me encaminhou direto para o Caps. No Caps, eu fiquei sendo atendida pelo doutor [...] Foi por um período de cinco meses. Ele me passava remédio, dizia que eu tinha depressão... mas eu não tinha depressão, e nem tenho! Os comprimidos me faziam muito mal... tinha ânsia de vômito, mal-estar, uma gastura... aí eu deixei de tomar... ainda voltei lá umas duas vezes, mas ele disse que eu não poderia deixar de tomar o remédio. Eu dizia: 'Doutor não tô precisando de remédio, eu preciso fazer uma readaptação de função, que é a única coisa que vai me deixar fora da sala de aula! Remédio eu não vou tomar porque eu não estou precisando de remédio!'. Foi então que o doutor me encaminhou para o Cerest (Participante 3).

Os relatos mencionados mostram três situações bem distintas de percurso do trabalhador na Renast. Em especial, os percursos dos participantes 2 e 3 evidenciam que os profissionais da atenção primária não investigaram a relação do sofrimento psíquico com o trabalho. Infere-se, pelo que já foi discutido na classe 4, 'Falhas na Renast', que faz uma análise do relato dos profissionais, uma insuficiência de capacitações oferecidas pelo Cerest aos profissionais de outros serviços (ESF e Caps), impactando na dificuldade em se estabelecer o nexo causal.

\section{Classe temática 3 - Ausência de ações do Cerest}

A classe temática 3 (25 UCEs; 4,49\% do corpus total) remete à ausência de ações do Cerest referentes à saúde mental nos locais de trabalho dos participantes. Em contraponto ao que seus profissionais relataram sobre as ações do Cerest de vigilância em saúde, os usuários entrevistados apontam que nunca presenciaram ações do Centro focadas em saúde mental, conforme relatos:

O meu processo não desencadeou nenhuma visita ou investigação no escritório para que melhore a gestão, que está muito ruim. Ela [gestora] está assediando todo mundo lá, mas ninguém sabe disso. O que falta na política pública é uma intervenção, acho que deveriam ir lá e levar alguma palestra, alguma orientação ou investigação se está ocorrendo em outros escritórios (Participante 1).

De vez em quando davam palestras [empresa], mas não adianta de nada porque lá é tudo muito rápido... tem que dar a produção. Não tinha esse negócio de fazer as coisas devagar não (Participante 2). 
No local de trabalho só se fala em calo na garganta, você acredita? Lá não tem ações [do Cerest] não, não tem palestras não (Participante 3).

Diante disso, esta classe reforça o que já foi apontado na Classe 4 - Falhas da Renast -, no tópico anterior, sobre o distanciamento das ações do Cerest em relação aos demais serviços de saúde. Os depoimentos da presente classe temática acrescentam a discussão sobre o distanciamento do Cerest em relação às empresas e organizações de trabalho. Sobre esse aspecto, Cardoso e Araújo (2016) apontam que a dimensão das necessidades em ST não são equivalentes à região atendida pelos Cerests, havendo mais demandas na região do que a capacidade que o centro consegue atender.

\section{Classe temática 4 - Investigação do nexo causal}

A classe temática 4 (56 UCEs; 10,07\% do corpus total) remete ao processo de investigação do nexo causal realizado pelos profissionais dos serviços. Os participantes relatam que os profissionais que o acolhem nos serviços, de início, não têm a sensibilidade de investigar o nexo causal da doença com o ambiente de trabalho.

Na primeira perícia que fiz, o médico poderia ter perguntado se era relacionado ao trabalho, mas não fez, não identificou isso. Os primeiros atestados do psiquiatra não identificavam relação com o trabalho, somente depois de meses é que ele relacionou ao ambiente de trabalho (Participante 1).

A integração entre os serviços (ESF, Caps e Cerest) configura-se como uma importante dificuldade para a investigação do nexo causal entre a doença e o trabalho. Apesar de explicitado que o SUS deve se pautar na integração entre os diversos níveis, na intersetorialidade e na integralidade, na prática, isso tem ocorrido apenas em experiências pontuais (Bernardo e Garbin, 2011). No caso da Saúde do Trabalhador, muitas vezes, parece haver mais abertura de outros órgãos públicos que estão fora do SUS para a interlocução com os Cerests - como Ministério do Trabalho, Ministério Público do Trabalho etc. - do que da própria rede de saúde.

Esta classe também mostra que, mesmo após ter iniciado uma investigação do nexo causal, nem sempre se tem como resultado final uma notificação. Infere-se que este fato se deve à ausência de médico no Cerest, conforme revela o relato a seguir:

Aqui no Cerest, a psicóloga disse que está faltando a médica e ela não pode fazer o laudo para a readaptação, tem que ser um médico (Participante 3). 
A fala do participante 3 complementa a análise anterior dos relatos dos profissionais ao constatar que há diversas falhas na Renast, dentre elas a subnotificação. Esta subnotificação dos casos em saúde mental no município é ocasionada pela ausência de profissional e insegurança técnica para o estabelecimento do nexo causal.

\section{Considerações finais}

Nesta pesquisa, evidenciou-se a falta da integração entre as redes (Renast e Raps) e entre os serviços (ESF, Caps e Cerest), além de atendimentos e encaminhamentos realizados sem a investigação e o estabelecimento do nexo causal entre sofrimento psíquico e trabalho. Evidencia-se a necessidade de que a Renast esteja sempre construindo articulações com os demais serviços de saúde e com outros setores da sociedade para que possa construir uma atenção mais integral em saúde. Para tanto, recomenda-se uma reorganização na rotina de trabalho da equipe técnica do Cerest, visando garantir a realização de ações como o Apoio Matricial em Saúde do Trabalhador. Com isso, garante-se uma aproximação efetiva das ações em saúde da família e das ações em saúde mental, possibilitando a realização de ações coletivas de prevenção, promoção e vigilância em ST.

A presente pesquisa oferece ainda feedback sobre os aspectos que podem ser revisados, em prol do constante progresso na eficácia e qualidade dos serviços de saúde. Pode-se elencar oportunidades de melhorias nos aspectos de: integralidade das ações com demais serviços, referência técnica na rede, apoio matricial e capacitação técnica dos demais serviços, vigilância em saúde, vigilância e controle epidemiológico e promoção de saúde.

Destaca-se como limitação da pesquisa a participação de poucos usuários e com coleta de dados de forma vertical. Surge como oportunidades para novas pesquisas a realização de um estudo longitudinal e a replicação da pesquisa em outros municípios do interior do país. Diante dos resultados apresentados, espera-se ter contribuído para a literatura sobre as políticas públicas em saúde, em especial na área de saúde do trabalhador.

\section{Colaboradores}

As três autoras participaram igualmente de todas as fases de elaboração do manuscrito e aprovaram a versão final do artigo. 


\section{Financiamento}

Não teve.

\section{LA OCULTACIÓN DEL DETERIORO PSÍQUICO DEL TRABAJADOR: LÍMITES DE LA INTEGRALIDAD EN LA RED DE ATENCIÓN DE LA SALUD}

Resumen El trabajo juega un papel fundamental para que el ser humano se mantenga socialmente productivo y reconocido. En este contexto, la salud mental ha recibido atención especial en las últimas décadas. En medio a la precarización, el menosprecio del trabajador, innovaciones tecnológicas y la inminencia del desempleo, se producen impactos negativos en la salud del trabajador y en consecuencia una mayor tasa de ausentismo por enfermedades psíquicas. El objetivo de esta investigación fue comprender cómo funciona la asistencia de la salud mental del trabajador en el Sistema Único de Salud en un municipio del interior del estado de Ceará (Brasil) y establecer si existe una relación causal entre salud, enfermedad y trabajo. Para esto se realizó una investigación de abordaje cualitativo que contó con 12 participantes - usuarios y profesionales que respondieron un guión de entrevista semiestructurado. La información de los profesionales se analizó con el software Iramuteq y la de los usuarios se sometió al análisis de contenido de Bardin. Los resultados indican fallas en las acciones propuestas por el Centro de Referencia en Salud del Trabajador, desarticulación de los servicios en la red, dificultad de investigación de la relación causal y consecuente insuficiencia en la notificación de los casos. Se concluye que es necesario crear vínculos entre los servicios de salud para lograr una atención más integral de la salud.

Palabras clave salud del trabajador; salud mental; políticas de salud; sistema único de salud. 


\section{Referências}

BARDIN, Laurence. Análise de conteúdo. Lisboa: Edições 70, 1997.

BERNARDO, Marcia H.; GARBIN, Andréia C. A atenção à saúde mental relacionada ao trabalho no SUS: desafios e possibilidades. Revista Brasileira de Saúde Ocupacional, São Paulo, v. 36, n. 123, p. 103-117, 2011.

BRASIL. Lei n. 8.080, de 19 de setembro de 1990. Dispõe sobre as condições para a promoção, proteção e recuperação da saúde, a organização e o funcionamento dos serviços correspondentes e dá outras providências. Disponível em: < http://www.planalto.gov. br/ccivil 03/leis/L8080.htm $>$. Acesso em: 01 fev. 2018.

BRASIL. Ministério da Saúde. Sobre a saúde do trabalhador. Brasília: MS, 2010.

BRASIL. Portaria n. 1.823, de 23 de agosto de 2012. Institui a Política Nacional de Saúde do Trabalhador e da Trabalhadora. Diário Oficial da República Federativa do Brasil, Ministério da Saúde, Brasília, DF, 2012.

BRASIL. Portaria n. 104 do MS/GM, de 25 de janeiro de 2011. Define as terminologias adotadas em legislação nacional, conforme o disposto no Regulamento Sanitário Internacional 2005 (RSI 2005), a relação de doenças, agravos e eventos em saúde pública de notificação compulsória em todo o território nacional e estabelece fluxo, critérios, responsabilidades e atribuições aos profissionais e serviços de saúde. Diário Oficial da República Federativa do Brasil, Ministério da Saúde, Brasília, DF, 2011.

BRASIL. Portaria n. 1679, de 19 de setembro de 2002. Dispõe sobre estruturação da rede nacional de atenção integral à saúde do trabalhador no SUS e dá outras providências. Diário Oficial da República Federativa do Brasil, Ministério da Saúde, Brasília, DF, 2002.

BRASIL. Portaria n. 777, 28 de abril de 2004. Dispõe sobre os procedimentos técnicos para a notificação compulsória de agravos à Saúde do Trabalhador em rede de serviços sentinela específica, no Sistema Único de Saúde-SUS. Diário Oficial da República Federativa do Brasil, Ministério da Saúde, Brasília, DF, 2004.

CAMARGO, Brigido V.; JUSTO, Ana M. Iramuteq: um software gratuito para análise de dados textuais. Temas em Psicologia, Ribeirão Preto, v. 21, n. 2, p. 513-518, 2013.

CAMPOS, Gastão W. S.; DOMITTI, Ana C. Apoio matricial e equipe de referência: uma metodologia para gestão do trabalho interdisciplinar em saúde. Cadernos de Saúde Pública, Rio de Janeiro, v. 23, n. 2, p. 399407, 2007.

CARDOSO, Mariana C. B.; ARAÚJO, Tânia M. Os Centros de Referências em Saúde do Trabalhador e as ações em saúde mental: um inquérito no Brasil. Revista Brasileira de Saúde Ocupacional, São Paulo, v. 41, e7, p. 1-14, 2016.

DUARTE, Renan F.; ALMEIDA, Victor H. $\mathrm{O}$ assédio moral como causador de doença ocupacional. Revista Laborativa, São Paulo, v. 4, n. 2, p. 4-25, 2015.

FONSECA, Wilson C. Análise do conteúdo. In: DUARTE, Jorge; BARROS, Antonio. Métodos e técnicas de pesquisa em comunicação. Rio de Janeiro: Atlas, 2005. p. 280-315.

LEÃO, Luís H. C.; VASCONCELLOS, Luiz C. F. Rede Nacional de Atenção Integral à Saúde do Trabalhador (Renast): reflexões sobre a estrutura de rede. Epidemiologia e Serviços de Saúde, Brasília, v. 20, n. 1, p. 85-100, 2011.

MACHADO, Jorge M. H. A propósito da vigilância em saúde do trabalhador. Ciência \& Saúde Coletiva, Rio de Janeiro, v. 10, n. 4, p. 987-92, 2005.

MACHADO, Jorge M. H. et al. Situação da Rede Nacional de Atenção Integral em Saúde do Trabalhador (Renast) no Brasil, 2008-2009. 
Revista Brasileira de Saúde Ocupacional, São Paulo, v. 38, n. 128, p. 243-256, 2013.

MEDINA, Flávia S.; MAIA, Maria Z. B. A subnotificação de LER/DORT sob a ótica de profissionais de saúde de Palmas, Tocantins. Revista Brasileira de Saúde Ocupacional, São Paulo, v. 41, e8, p. 41-54, 2016.

MELO, Cynthia F. et al. Avaliação da estratégia saúde da família em Natal a partir das crenças dos seus colaboradores. Psico, Porto Alegre, v. 44, n. 4, p. 533-541, 2013.

MELO, Cynthia F. et al. Avaliação da Estratégia Saúde da Família em Natal a partir das crenças dos seus usuários. Revista de Pesquisa: Cuidado é Fundamental (Online), Rio de Janeiro, v. 9, p. 620-626, 2017.

MELO, Cynthia F. et al. Desenvolvimento de instrumentais para avaliação da estratégia saúde da família em Natal. Psicologia: Reflexão e Crítica, Porto Alegre, v. 27, n. 2, p. 219-227, 2014.

PAPARELLI, Renata; SATO, Leny; OLIVEIRA, Fábio. A Saúde Mental relacionada ao trabalho e os desafios aos profissionais da saúde. Revista Brasileira de Saúde Ocupacional, São Paulo, v. 36, n. 123, p.118-127, 2011.

PINTO, Diego M. et al. Projeto terapêutico singular na produção do cuidado integral: uma construção coletiva. Texto Contexto Enfermagem, Florianópolis, v. 20, n. 3, p. 493-502, 2011.

POÇO, Cristiane R. V.; POÇO, José L. C. O Sistema de Informação do Acolhimento do Cerest de Juiz de Fora/MG: construindo indicadores de fluxos e atenção em saúde do trabalhador. Revista Médica de Minas Gerais, Minas Gerais, v. 25, n. 4, p. 548-555, 2015.
SANTOS, Ana P. L.; LACAZ, Francisco A. C. Apoio matricial em saúde do trabalhador: tecendo redes na atenção básica do SUS, o caso de Amparo/SP. Ciência \& Saúde Coletiva, Rio de Janeiro, v. 17, n. 5, p. 1.143-1.150, 2012.

SELIGMANN-SILVA, Edith et al. O mundo contemporâneo do trabalho e a saúde mental do trabalhador. Revista Brasileira de Saúde Ocupacional, São Paulo, v. 35, n. 122, p. 187191, 2010.

SILVA, Eli B. F. et al. Transtornos mentais e comportamentais: perfil dos afastamentos de servidores públicos estaduais em Alagoas, 2009. Epidemiologia e Serviços de Saúde, Brasília, v. 21, n. 3, p. 505-514, 2012.

SILVA, Patrícia C.; MERLO, Álvaro R. C. Prazer e sofrimento de psicólogos no trabalho em empresas privadas. Psicologia: Ciência e Profissão, Brasília, v. 27, n. 1, p. 132-147, 2007.

SILVESTRE, Mirian P.; SABINO, Marcos O. Interfaces LER/saúde mental: a experiência de um centro de referência em saúde do trabalhador do estado de São Paulo. Revista Brasileira de Saúde Ocupacional, São Paulo, v. 36, n. 123, p. 128-138, 2011.

SOARES, Carlos H. A.; LINHARES, Maria S. C. Vigilância à saúde no município de Sobral-CE: aspectos históricos, conceituais e atuação na saúde pública. SANARE - Revista de Políticas Públicas, Sobral, v. 7, n. 1, p. 6-11, 2008.

TORRES, Amélia R. A. et al. Construção participativa de uma linha de cuidado ao trabalhador com Lesão por Esforços Repetitivos. Revista Rene, Fortaleza, v. 17, n. 5, p. 626 635, 2016 